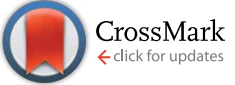

Cite this: RSC Adv., 2017, 7, 17336

Received 12th January 2017

Accepted 14th March 2017

DOI: $10.1039 / \mathrm{c} 7 \mathrm{ra00514h}$

rsc.li/rsc-advances

\title{
A bioinspired heterogeneous catalyst based on the model of the manganese-dependent dioxygenase for selective oxidation using dioxygen $\uparrow$
}

\author{
Jérémy Chaignon, ${ }^{\mathrm{ab}}$ Marie Gourgues, ${ }^{\mathrm{ac}}$ Lhoussain Khrouz, ${ }^{a}$ Nicolás Moliner, ${ }^{\mathrm{b}}$ \\ Laurent Bonneviot, ${ }^{a}$ Fabienne Fache ${ }^{c}$ Isabel Castro ${ }^{* b}$ and Belén Albela*a
}

\begin{abstract}
A hybrid bioinspired material with manganese(॥) complexes grafted on the surface of a mesostructured porous silica is investigated. The Mn sites mimic the manganese-dependent dioxygenase (MndD), which is an enzyme that catalyses the oxidation of catechol derivatives. The metal complexes were introduced in the silica using a dinuclear complex $\left[\mathrm{Mn}_{2} \mathrm{~L}_{2}(\mathrm{Cl})_{2}(\mu-\mathrm{Cl})_{2}\right]$ as a precursor with a clickable ligand $N, N^{\prime}$-bis [(pyridin-2-yl)methyl]prop-2-yn-1-amine (L). Azide moieties covalently grafted on MCM-41 type mesoporous silica were utilised to anchor the manganese complex through Huisgen cycloaddition using $\mathrm{CuBr}\left(\mathrm{PPh}_{3}\right)_{3}$ as a catalyst. A second functional group - trimethylsilyl or pyridine-was grafted on the silica to bring, together with nanopore size confinement, a similar metal environment as in MndD. The mesostructure of the materials was maintained after incorporation of the $\mathrm{Mn}$ complex. Catalytic oxidation of 3,5-di-t-butyl-catechol (3,5-DTBC) into quinone occurred without the need of an additional base when the metal complex was confined in the porous solid. In comparision, the oxidation of 4-tbutyl-catechol (4-TBC) that always required a basic media led to a total oxidation into the orthoquinone, contrary to the molecular analogue.
\end{abstract}

\section{Introduction}

Many industrial processes involve catalytic reactions, since they allow working under milder conditions with high selectivity and short reaction time, decreasing, therefore, the cost of the final product. ${ }^{1}$ However, these enhanced processes are not a prerogative for industry, for they existed in nature long before chemists could understand them. A class of natural metalloproteins called metalloenzymes is able to carry out extremely specific reactions under physiological conditions (between 10 and $40{ }^{\circ} \mathrm{C}$ for most of them). ${ }^{2}$ In particular, several metalloenzymes called oxygenases perform the oxidation of organic compounds by activating molecular dioxygen. Various metal ions can be found in these oxygenases, mainly copper, iron and manganese. $^{3-9}$ Although the reaction with dioxygen is thermodynamically favourable, the electronic configuration of the $\mathrm{O}_{2}$ molecule creates a strong kinetic barrier that requires

${ }^{a}$ Laboratoire de Chimie UMR CNRS 5182, Ecole Normale Supérieure de Lyon, University of Lyon, 46, Allée d'Italie, 69364 Lyon, Cedex-07, France. E-mail: belen. albela@ens-lyon.fr

${ }^{b}$ Instituto de Ciencia Molecular, Universitat de València, C/Catedrático José Beltrán 2, 46980 Paterna, València, Spain.E-mail: isabel.castro@uv.es

'Institut de Chimie et Biochimie Moléculaires et Supramoléculaires (ICBMS) UMR CNRS 5246, University of Lyon, Bd. du 11 Novembre 1918, 69622 Villeurbanne, Cedex, France

$\dagger$ Electronic supplementary information (ESI) available: TGA profiles of materials, magnetic measurements and $\mathrm{N}_{2}$ sorption isotherms. See DOI: 10.1039/c7ra00514h activation, which is useful to prevent any spontaneous reaction of $\mathrm{O}_{2}$ with organic molecules.

Structural and mechanistic research on metalloenzymes in the past decades has allowed the development of numerous bioinspired systems that can be used for catalysis. Homogeneous biomimetic complexes are often not optimal for reactions involving dioxygen activation. Indeed, the activation of oxygen can partially oxidise the catalyst. Grafting on a solid support can stabilise the catalyst and confer confinement as in the enzymatic pocket.

Amongst oxygenases, a recurrent metal coordination triad is observed, composed by two histidines (His) and one carboxylic acid, coming either from glutamate (Glu) or aspartate (Asp) moieties. This widespread structural motif is called the 2-His-1-carboxylate facial triad, and is found in many metalloproteins. ${ }^{6}$ This is the case of catechol dioxygenase, which catalyses the cleavage of catechol derivatives. Two kinds of catechol dioxygenases can be found, which differ on the nature of the metal ion involved at the active site: $\mathrm{Fe}^{\mathrm{III}}$ allows an intradiol cleavage while $\mathrm{Fe}^{\mathrm{II}}$ or $\mathrm{Mn}^{\mathrm{II}}$ performs the extradiol one. $^{6-9}$ In particular, the manganese-dependent dioxygenase (MndD) is a system that has attracted much attention since its catalytic mechanism is still under discussion., ${ }^{70-12}$ Therefore, the study of bioinspired systems that mimic the structural and/or catalytic function of MndD could help to understand its reaction mechanism. 
Molecular models that contain a manganese centre are however much less frequent than those containing iron. Only few examples in the literature report manganese(II) complexes as mimics of the catechol dioxygenase. The first reported model to our knowledge was synthesised by Sakurai et al. two years after the discovery of MndD. ${ }^{13}$ Their report describes the use of penicillamine with manganese(II) in the oxidation of catechol to the corresponding muconic acid derivatives resulting from a true extradiol dioxygenase activity. However, very low conversion rates were achieved $(<2 \%)$. Ramadan and El-Mehasseb subsequently investigated the oxidative properties of manganese(II) with tridentate pyridyl hydrazone ligands. ${ }^{\mathbf{1 4}}$ They reported the transformation of catechol into $o$ benzoquinone in presence of catalyst and $\mathrm{O}_{2}$, which would correspond to an oxidase activity (oxidation without incorporation of oxygen atom in the substrate). Similar results were obtained a few years later with tetradentate ligands containing imidazole, phenolate and/or pyridine moieties. ${ }^{15}$ At the same time, the manganese(II) complex of another tetradentate ligand, $N, N^{\prime}$-bis(2-pyridylmethyl)-1,2-ethanediamine (bispicen), managed to oxidise the 4-tert-butylcatechol into its quinone equivalent mixed with extradiol intermediates. ${ }^{16}$ Reaction conditions turned out to have an important effect on the resulting products.

We have developed a bioinspired approach for design of the metal supported catalysts based on the model of metalloproteins. ${ }^{17-21}$ This approach was recently applied using the manganese dependent dioxygenase (MndD) as a model, the $N, N^{\prime}$-bis[(pyridin-2-yl)methyl]prop-2-yn-1-amine (L) as a clickable ligand for grafting and $\left[\mathrm{Mn}_{2} \mathrm{~L}_{2}(\mathrm{Cl})_{2}(\mu-\mathrm{Cl})_{2}\right]$ as a precursor metal complex (Scheme 1). ${ }^{18}$ This ligand has the particular advantage to mimic the facial triad present in the active site of the MndD and allows an efficient grafting in the silica support. ${ }^{22-25}$ Indeed, the alkyne side function allows grafting of the ligand in an azido-functionalised support using "click chemistry". ${ }^{26-28}$ In addition, the two pyridine and the tertiary amine functions present in the ligand can coordinate to the $\mathrm{Mn}$ (II) ion and thus mimic the metal environment of the MndD.

In the present work we are going further in providing a comprehensive investigation of the $\left[\mathrm{Mn}_{2} \mathrm{~L}_{2}(\mathrm{Cl})_{2}(\mu-\mathrm{Cl})_{2}\right]$ grafting, knowing that this dimer is in equilibrium with the monomer in solution. ${ }^{18}$ We will also compare two different local environments of the metal complex in the solid to test the influence of a pyridine side function meant here to mimic the histidine function neighbouring the metal active site in MndD. Both homogeneous and heterogeneous systems are tested for the first time on the oxidation of catechol derivatives.

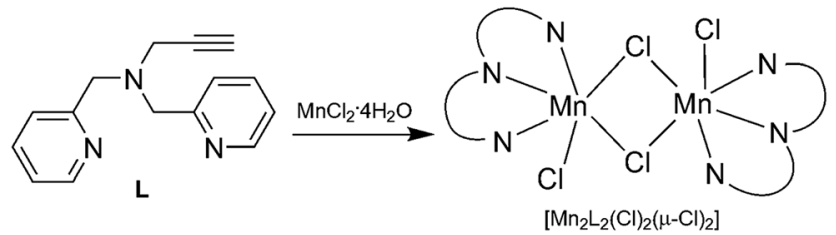

Scheme 1 Synthesis of complex $\left[\mathrm{Mn}_{2} \mathrm{~L}_{2}(\mathrm{Cl})_{2}(\mu-\mathrm{Cl})_{2}\right]$.

\section{Results and discussion}

Incorporation of the $\mathrm{Mn}^{\mathrm{II}}$ complex in the mesoporous silica: synthesis strategy to isolate the metal sites with control of their close environment

The alkyne function present in the ligand $\mathbf{L}$ (Scheme 1) was used to covalently graft the manganese complex into the pores of a mesoporous silica of the LUS type, which presents a $2 \mathrm{D}$ hexagonal structure just like the classic MCM-41 silica. ${ }^{29}$ The LUS silica was synthesised using a ultra-fast microwave assisted hydrothermal synthesis that affords a high quality mesostructured porous silica. ${ }^{30}$ Due to the yield and selectivity advantages of the copper(I)-catalysed Huisgen azide-alkyne cycloaddition (also known as "click chemistry"), this reaction was chosen for the grafting process. ${ }^{26-28}$ We had the choice to design our ligands either with an azide or an alkyne arm, the latter being preferred for two reasons. First, the incorporation of an azide function in the ligand could have been more problematic for the synthesis of the complex than the incorporation of an alkyne arm because of the coordinating potential of the azide moiety. Secondly, the synthesis of the azide tethering silane was easier than the alkyne tether, the azidopropyltriethoxysilane precursor being then synthesised starting from chloropropyltriethoxysilane upon nucleophilic substitution of the chlorine atom by an azide moiety. ${ }^{31}$

The molecular stencil patterning (MSP) technique was used to incorporate the complexes into the solid (Scheme 2). ${ }^{32-34}$ This strategy takes advantage of the cationic nature of the surfactant (cetyltrimetylammonium, $\mathrm{CTA}^{+}$) present in the mesoporous silica. The general procedure is a four step strategy: (i) the template is partially removed with hydrochloric acid; due to electrostatic repulsion, the remaining surfactant rearranges thus making some silica surface available, (ii) a first organosilane (F1) is grafted onto this freed surface, (iii) all of the remaining surfactant is removed, freeing silica surface once again, and (iv) the second function (F2) is grafted, providing a double functionalised material. In the present work, however, a slightly different protocol was applied where $\mathrm{CTA}^{+}$was exchanged with tetramethylammonium $\left(\mathrm{TMA}^{+}\right)$prior to the first partial extraction (Scheme 2). ${ }^{34}$ This modification allowed

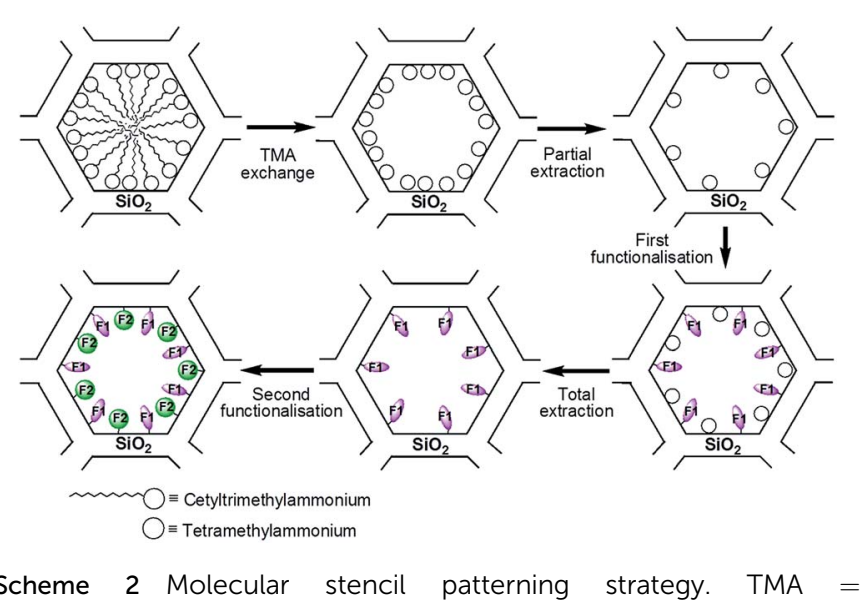
tetramethylammonium. 
a better diffusion of the F1 grafting function since there was more available pore space. If the grafted functions are modelled as spheres arranged in $2 \mathrm{D}$ hexagonal packing on the pore surface, isolating a function F2 will result in having it surrounded by 6 functions F1. Every F1 will thus be adjacent to 3 functions F2, which corresponds to a ratio F1/F2 of $2 .^{32}$

The nomenclature used for the synthesised solids is the following. LUS stands for the as-made support containing $\mathrm{CTA}^{+}$ molecules inside the pores, while the material exchanged with $\mathrm{TMA}^{+}$is denoted as LUS-TMA. Partial extraction is represented by an - Ex suffix where $x$ is the percentage of extracted TMA ${ }^{+}$. For instance, a material where $15 \%$ of $\mathrm{TMA}^{+}$was extracted is named LUS-TMA-E15. Totally extracted materials are simply noted LUS-E. Likewise, when the remaining $\mathrm{TMA}^{+}$is removed from a LUS-TMA-Ex material, the resulting one is denoted as LUS-Ex. Grafting reactions are symbolised by prefixes. For instance, silica functionalised with azide $\left(\mathrm{N}_{3}\right)$ and trimethylsilyl (TMS) groups will be named $\mathrm{N}_{3}$-TMS@LUS. In the case of double functionalisation, the last function incorporated is placed at the beginning of the name: a material functionalised with F1 and then with F2 will thus be called F2-F1@LUS.

In the present work two materials containing a manganese(II) complex were studied using $\left[\mathrm{Mn}_{2} \mathrm{~L}_{2}(\mathrm{Cl})_{2}(\mu-\mathrm{Cl})_{2}\right]^{18}$ as metal precursor: a new solid $\{$ Mn $\}$-Py@LUS-E15 (S1), where pyridine (Py) functions are in the vicinity of the metal complexes, and the already reported $\{\mathrm{Mn}\}$-TMS@LUS-E (S2), ${ }^{18}$ where the manganese complexes are surrounded by hydrophobic trimethylsilyl (TMS) functions (Scheme 3). In this nomenclature, the $\{\mathrm{Mn}\}$ function is the product of the reaction between $\left[\mathrm{Mn}_{2} \mathrm{~L}_{2}(\mathrm{Cl})_{2}(\mu-\mathrm{Cl})_{2}\right]$ and the azide $\left(\mathrm{N}_{3}\right)$ tether present in both host materials. The TMS function was chosen to mimic some hydrophobic residues present in the enzymatic pocket of the metalloprotein, whereas Py function was selected to mimic the His200 residue present in the second coordination sphere of the $\mathrm{Mn}$ active site, which is known to help in the activation of molecular oxygen during the catalytic cycle of MndD.7,35,36

\section{Optimisation of the "click chemistry" grafting of the Mn complex}

Even though click chemistry is known to be efficient, one must be careful about the conditions implied in those reactions. Indeed, the copper-catalysed Huisgen cycloaddition has proven to be sensitive to coordinating molecules when the classical copper catalyst is used. In principle, copper(II) sulphate or acetate is directly used and reduced to copper(I) in situ, most of the time by treatment with sodium ascorbate. For instance,

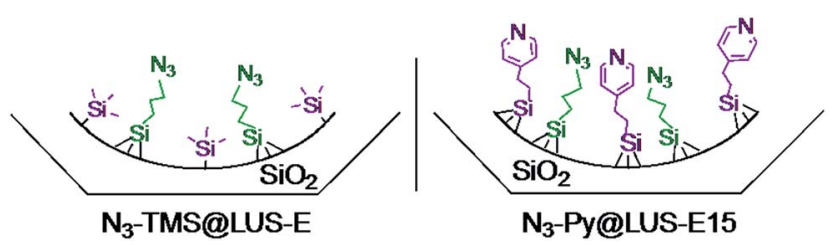

Scheme 3 Host materials for the grafting of the $\mathrm{Mn}\left(\right.$ (I) complex: $\mathrm{N}_{3}-$ TMS@LUS-E and $\mathrm{N}_{3}$-PyQLUS-E15. reaction with $\mathbf{L}$ and benzyl azide has been reported and performed under these conditions. ${ }^{37}$ Instead of sodium ascorbate, methanol can also be used as reductant. ${ }^{38}$ Some preliminary tests between the ligand $\mathbf{L}$ and azidopropyltrimethoxysilane were performed in order to optimise the conditions for the click reaction on the solid support. Under these conditions, coordination of copper to the ligand $\mathbf{L}$ was observed in all cases, even when copper(I) bromide was used. A tris(triphenylphosphine) copper(I) bromide complex was required as catalyst to avoid this problem. This change of catalyst was inspired by organic syntheses of triethoxysilanes using the microwave-assisted Huisgen copper-catalysed reaction reported in the literature. ${ }^{39}$ Given that triethoxysilanes are particularly sensitive to water and to many chemical functions such as alcohols or carboxylic acids, this kind of synthesis was quite a challenge. However, using microwave irradiation and $\operatorname{CuBr}\left(\mathrm{PPh}_{3}\right)_{3}$ as catalyst, the desired organosilane was obtained in a yield typical for click chemistry (above 90\%).

Then, several tests were performed to click the manganese(II) complex $\left[\mathrm{Mn}_{2} \mathrm{~L}_{2}(\mathrm{Cl})_{2}(\mu-\mathrm{Cl})_{2}\right]$ in the azide-functionalised silica $\mathrm{N}_{3}$ @LUS-E. After an overnight reaction with $\mathrm{CuBr}\left(\mathrm{PPh}_{3}\right)_{3}$, the IR spectrum of the resulting material still exhibited a band around $2100 \mathrm{~cm}^{-1}$, which is characteristic of the presence of azide moieties. After a one-week reaction, no absorption occurred in this region, proving that all the azide moieties had reacted. This long reaction time can be explained by the porous nature of the material. All the reactive sites at the silica surface are not as accessible as in solution, and diffusion inside the porous material becomes a non-negligible parameter. Removal of the copper catalyst was performed by washing with methanol. This technique was efficient enough to remove the catalyst, as confirmed by EDX microscopy, EPR and elemental analysis: no trace of copper could be found beyond the detectable threshold. Therefore, this technique was applied to incorporate the manganese complex into the host materials $\mathrm{N}_{3}$-Py@LUS-E15 and $\mathrm{N}_{3}$-TMS@LUS-E, affording solids \{Mn\}-Py@LUS-E15 (S1), \{Mn\}-TMS@LUS-E (S2), respectively.

\section{Characterisation of the hybrid materials}

The porous structure of the host materials was checked using powder X-ray diffraction (XRD) during the different steps of the synthesis. The original 2D hexagonal porous structure was maintained during the functionalisation of the silica and the incorporation of the manganese complex (Fig. 1).

Thermogravimetric analyses (TGA) indicate that after exchange of $\mathrm{CTA}^{+}$surfactant molecules present in the as-made silica by $\mathrm{TMA}^{+}$, almost $2 / 3$ of the internal surface of the silica was covered by $\mathrm{TMA}^{+}$cations, which corresponds to $2.1 \mathrm{mmol}$ of $\mathrm{TMA}^{+}$per gram of $\mathrm{SiO}_{2}$. Starting from this solid, two intermediate materials were synthesised:TMS@LUS-TMA and Py@LUSTMA-E15. In order to obtain a F1/F2 molar ratio of 2, TMS functionalisation was performed without any partial extraction. Indeed, TMS is grafted to the support with only one covalent bond and the ammonia generated by the aperture of the azasilane used for the functionalisation displaces a small part of the $\mathrm{TMA}^{+}$. However, in the case of pyridine, which possesses 


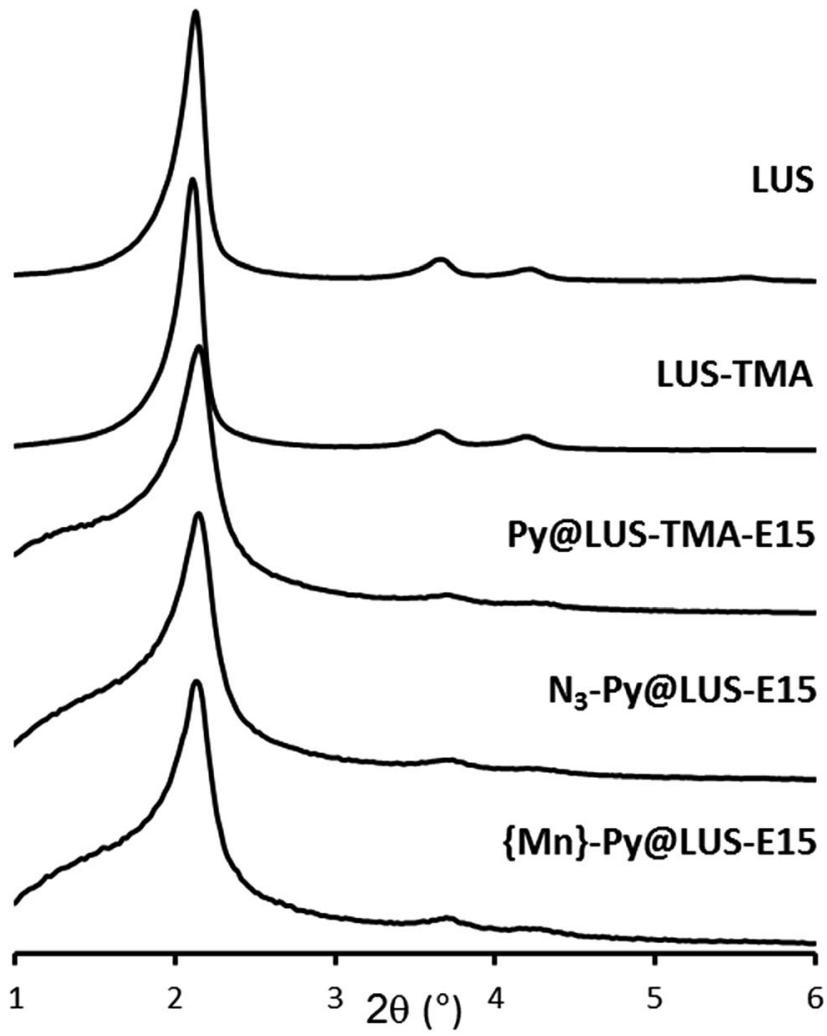

Fig. 1 Powder XRD patterns of the support LUS-E and the materials LUS-TMA, Py@LUS-TMA-E15, N3-Py@LUS-E15 and \{Mn\}-Py@LUSE15 (S1).

a triethoxysilane tether function, $15 \%$ of $\mathrm{TMA}^{+}$was extracted before the functionalisation reaction in order to favour the grafting of the function. In other words, TMS functionalisation was performed on LUS-TMA material while pyridine functionalisation was carried out with LUS-TMA-E15 material. The F1/F2 molar ratio was calculated from TGA, elemental analyses, and quantitative solid ${ }^{29}$ Si-NMR (Table 1 and Fig. S1 $\dagger$ ). Py/ $\mathrm{N}_{3}$ and $\mathrm{TMS} / \mathrm{N}_{3}$ molar ratios of 1.9 and 1.8 can be deduced, and these are close to the desired value of 2.0 required to insure site isolation. Note that the TMS amount cannot be precisely deduced neither from TGA - the mass loss is very low and occurs in a broad temperature range - nor from elemental analyses due to the presence of carbon atoms in $\mathrm{TMA}^{+}$.

Table 1 Data deduced from $\mathrm{N}_{2}$ sorption isotherms, TGA, elemental analyses and quantitative solid ${ }^{29} \mathrm{Si} \mathrm{NMR}^{a}$

\begin{tabular}{llllll}
\hline Material & $V_{\mathrm{p}}{ }^{b}\left(\mathrm{~cm}^{3} \mathrm{~g}^{-1}\right)$ & $M_{\mathrm{n}}(\mathrm{wt} \%)$ & $\mathrm{F} 1 / \mathrm{Si}^{c}$ & $\mathrm{~F} 2 / \mathrm{Si}^{d}$ & $\mathrm{Cl} / \mathrm{Mn}^{e}$ \\
\hline LUS-E & 0.86 & - & - & - & - \\
$\mathrm{N}_{3}$-TMS@LUS-E & 0.26 & - & 0.046 & 0.025 & - \\
$\mathrm{N}_{3}$-Py@LUS-E15 & 0.28 & - & 0.064 & 0.034 & - \\
S1 $^{18}$ & 0.31 & 1.7 & - & - & 0.7 \\
S2 & 0.22 & 2.4 & - & - & 0.5
\end{tabular}

${ }^{a}\{$ Mn $\}$-Py@LUS-E15 = S1; $\{$ Mn $\}$-TMS@LUS-E $=$ S2. ${ }^{b}$ Porous volume deduced from sorption $\mathrm{N}_{2}$ isotherms using $t$-plot, $\pm 0.01 \mathrm{~cm}^{3} \mathrm{~g}^{-1}$. ${ }^{c}$ Molar ratio, $\mathrm{F} 1=$ TMS or Py. ${ }^{d}$ Molar ratio, $\mathrm{F} 2=\mathrm{N}_{3} .{ }^{e}$ Molar ratio, deduced from chemical analyses.

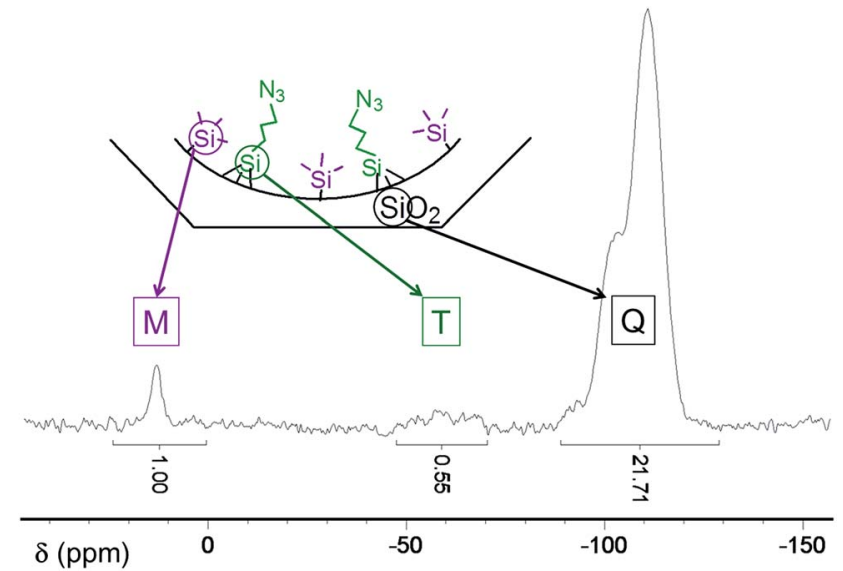

Fig. 2 Solid ${ }^{29}$ Si HPDEC NMR spectrum of $\mathrm{N}_{3}-$ TMSQLUS-E.

Integration of $\mathrm{M}$ and $\mathrm{Q}$ massifs from solid ${ }^{29} \mathrm{Si}-\mathrm{NMR}$ could however give a precise value of the quantity of grafted TMS functions per gram of $\mathrm{SiO}_{2}$ (Fig. 2).

The two hybrid materials $\{\mathrm{Mn}\}$-Py@LUS-E and $\{\mathrm{Mn}\}$ TMS@LUS-E present a manganese weight loading of about $2 \%, 1.7$ and $2.4 \%$, respectively (Table 1 ). The chloride counteranions present in the initial manganese complex are only partially retained in the final materials. The $\mathrm{Cl} / \mathrm{Mn}$ molar ratio in the grafted materials $(\mathrm{Cl} / \mathrm{Mn}=0.7$ and 0.5 for $\{\mathrm{Mn}\}$-Py@LUS$\mathrm{E}$ and $\{\mathrm{Mn}\}$-TMS@LUS-E, respectively) is approximately $25 \%$ of the original chloride anions present in the dinuclear precursor $(\mathrm{Cl} / \mathrm{Mn}=2)$. This diminution tends to prove that the chloride bridges are partially lost during the grafting process questioning about the presence of mononuclear species.

Nitrogen sorption isotherms were performed to measure the remaining porous volume of the final materials (Table 1 and Fig. 3). The pore volume, measured using the $t$-plot method, was reduced from $0.86 \mathrm{~cm}^{3} \mathrm{~g}^{-1}$ in LUS-E down to $0.2-$ $0.3 \mathrm{~cm}^{3} \mathrm{~g}^{-1}$ in the final materials, indicating a partial filling of

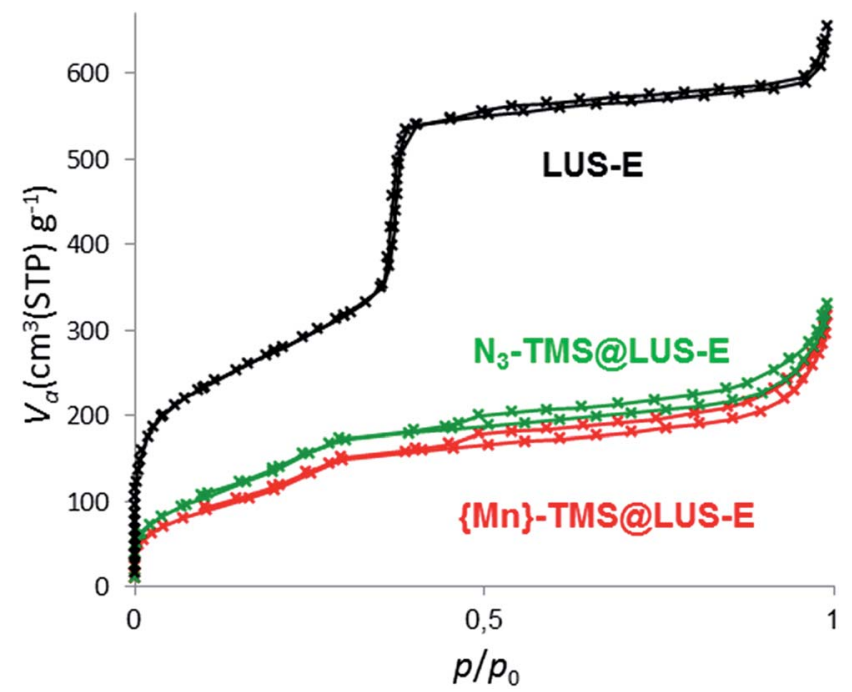

Fig. 3 Nitrogen sorption isotherms at $77 \mathrm{~K}$ of LUS-E, N $3-T M S @ L U S-E$, $\{M n\}-T M S @ L U S-E(S 2)$. 
the pores after the incorporation of the complex. However, there was still enough pore volume to allow the substrate diffusion and its access to the manganese(II) centres for catalytic applications.

\section{Nature of the metal complexes inside the solid}

In order to determine the relative amount of mono- and dinuclear species, magnetic and EPR measurements were performed for both solids \{Mn\}-Py@LUS-E15 (S1), \{Mn\}TMS@LUS-E (S2).

The magnetic properties of $\mathbf{S 1}$ and $\mathbf{S} 2$ are shown in Fig. 4 and $\mathrm{S} 2 \uparrow$ in the form of the $\chi_{\mathrm{M}} T$ vs. $T$ plot $\left(\chi_{\mathrm{M}}\right.$ being the molar magnetic susceptibility per $\mathrm{Mn}^{\mathrm{II}}$ ion and $T$ the absolute temperature). They are qualitatively similar to those of the dinuclear precursor $\left[\mathrm{Mn}_{2} \mathrm{~L}_{2}(\mathrm{Cl})_{2}(\mu-\mathrm{Cl})_{2}\right] \cdot{ }^{18} \chi_{\mathrm{M}} T$ remains constant from room temperature down to $c a .100 \mathrm{~K}$ and it abruptly decreases upon further cooling, suggesting the occurrence of weak antiferromagnetic interactions between the $\mathrm{Mn}^{\mathrm{II}}$ ions within the grafted metal complex. The least-squares fits of the experimental data through the appropriate expression derived from the spin Hamiltonian for an antiferromagnetically coupled dinuclear manganese(II) complex $\left(H=-J S_{1} S_{2}\right){ }^{18}$ assuming the presence of a variable amount of mononuclear manganese(II) species $(\alpha)$, gave $J=-1.5 \mathrm{~cm}^{-1}$ and $g=2.0$ for both S1 and S2 with $\alpha=0.25$ (S1) and 0.38 (S2) (solid lines in Fig. 4 and $\mathrm{S} 2 \dagger)$. The calculated $\alpha$ values indicate the presence of a relatively larger amount of mononuclear $\mathrm{Mn}^{\mathrm{II}}$ species resulting from the loss of the two bridging chlorides in S2, in agreement with the slightly smaller value of the $\mathrm{Cl} / \mathrm{Mn}$ ratio, as discussed above.

The calculated $-J$ value in $\mathbf{S 1}$ and $\mathbf{S 2}$ materials are twenty five-fold larger than that found for the dinuclear precursor $(J=$ $\left.-0.059 \mathrm{~cm}^{-1}\right) .{ }^{18}$ The stronger antiferromagnetic coupling for

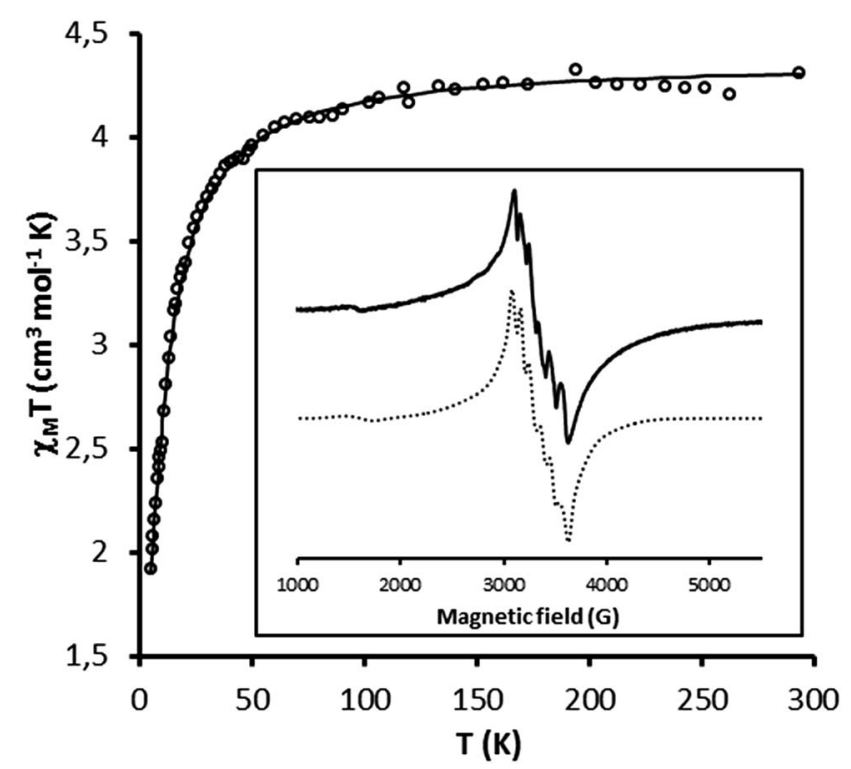

Fig. 4 Temperature dependence of $\chi_{M} T$ for S1. The solid line represents the best fit discuss in the text. Insert: solid-state EPR spectra of S1 at $120 \mathrm{~K}$ and its simulation (dotted line). the grafted metal complex could be explained by the bending of the $\mathrm{Mn}-\mathrm{Cl}-\mathrm{Mn}$ angle $(\theta)$ within the double-bridged $\mathrm{Mn}_{2}(\mu-\mathrm{Cl})_{2}$ diamond core with respect to that found in the dinuclear precursor $\left(\theta=97.5^{\circ}\right) .{ }^{18}$ This situation agrees with the general trend found in related double-bridged $\mathrm{di}-\mu$-chlorodimanganese(II) complexes reported in the literature, which exhibit weak ferro- $\left(J=0.66-1.1 \mathrm{~cm}^{-1} \text { with } \theta=93.5-96.4^{\circ}\right)^{40-42}$ to moderate antiferromagnetic couplings $\left(-J=4.8-5.2 \mathrm{~cm}^{-1}\right.$ with $\left.\theta=90.2-90.7^{\circ}\right) .^{43,44}$ Overall, these results suggest that the molecular structure of the dinuclear precursor was likely modified upon grafting within the pore walls of the mesoporous silica.

EPR spectra of $\mathbf{S 1}$ and $\mathbf{S} 2$ solids confirmed the presence of both monomeric and dimeric Mn species. In both cases the spectra were simulated assuming the monomeric ratio $\alpha$ deduced from the magnetic measurements (Fig. 4 and $\mathrm{S} 2 \dagger$ ). The shape of the simulated signals matched well that of the experimental signals assuming one type of monomer and two types of dimers, a dimer 1 with $D=0.0333 \mathrm{~cm}^{-1}$ and a dimer 2 with $D=0.0733 \mathrm{~cm}^{-1}$. The calculated parameters for the different species were: for S1, 62.5\% of dimer 1 with $g=[1.990$ 1.9902 .120 ], $12.5 \%$ of dimer 2 with $g=$ [2.000 2.000 2.150], 25\% of monomer with $g=\left[\begin{array}{ll}2.055 & 2.018 \\ 1.940\end{array}\right]$, and for S2, 28\% of dimer 1 with $g=\left[\begin{array}{lll}1.9902 .0002 .130\end{array}\right], 34 \%$ of dimer 2 with $g=$ $\left[\begin{array}{lll}1.990 & 2.100 & 2.200\end{array}\right], 38 \%$ of monomer with $g=\left[\begin{array}{ll}2.080 & 2.010\end{array}\right.$ 1.940] (see $\mathrm{ESI} \dagger$ for additional parameters). The presence of two different dimers revealed by EPR is not surprising given the various possibilities of interaction with the functionalised material or the triazole cycle generated during the Huisgen cycloaddition. The $\mathrm{Cl} / \mathrm{Mn}$ molar ratio deduced from the elemental analysis for $\mathbf{S 1}$ and $\mathbf{S 2}$ (0.7 and 0.5, respectively) led us to suppose that the solid likely contains a dimer 1 with two chloride bridges, a dimer 2 with one chloride bridge and a monomer without any chloride ion in the first coordination sphere (Scheme 4 and Fig. S2 $\dagger$ ). Considering this hypothesis, the calculated $\mathrm{Cl} / \mathrm{Mn}$ molar ratios would be 0.68 and 0.45 for $\mathrm{S1}$ and $\mathbf{S 2}$, respectively, which are within the margin of error of elemental analysis. In addition, the difference of $g$ values for dimer 2 in both solids could be explained either by the presence of a second bridge provided by the different supports or by a different geometry around the metal ion induced by the solid matrix.

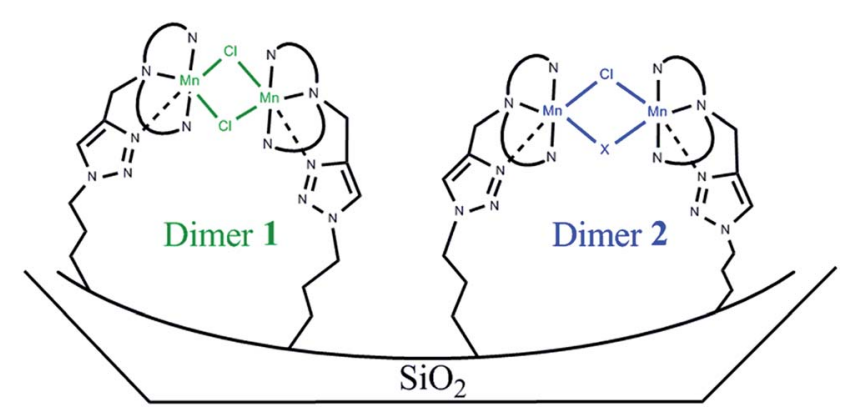

Scheme 4 Representation of dimers 1 and 2. X represents a possible second bridge for dimer 2 . Dashed bonds are possible bonds created after the click reaction. 


\section{Catalytic properties}

We first tested the oxidation of 3,5-di-t-butylcatechol $(3,5$ DTBC), known to be easier to study if compared to catechol, as it leads to more stable intermediates and thus to fewer byproducts, due to the presence of 3- and 5-t-butyl blocked positions. ${ }^{45}$ In order to appreciate the effect of the manganese complex anchoring into the mesoporous silica, we systematically compared the heterogeneous catalyst and its homogeneous analogue. We mainly identified one product, named $\mathrm{A}$, which is the quinone equivalent of 3,5-DTBC (Scheme 5) and confirmed the oxidase activity of our catalysts (Table 2). ${ }^{\mathbf{1 4}}$

Without any catalyst and in the presence of a base (Table 2, entry 1), a mixture of unidentified products and the starting material was obtained. In the absence of base, no reaction occurred, without or with $\mathrm{MnCl}_{2}$ as catalyst (entries 0 and 2, respectively). In homogeneous conditions, with a catalytic amount of base $(10 \%)$, complete conversion was observed and product A was isolated exclusively whatever the catalyst used, i.e. $\mathrm{MnCl}_{2}$ or $\left[\mathrm{Mn}_{2} \mathrm{~L}_{2}(\mathrm{Cl})_{2}(\mu-\mathrm{Cl})_{2}\right]$ (entries 3 and 4). Working under reflux did not change the reactivity (entry 5).

Heterogeneous catalysts led also to product A even in the absence of an additional base (entries 6 and 7 for $\{\mathrm{Mn}\}$ Py@LUS-E15 and \{Mn\}-TMS@LUS-E, respectively). It is not surprising since it was already observed that pyridine has a negligible effect on this reaction contrary to triethylamine. ${ }^{\mathbf{4 6}}$ Nevertheless, our heterogeneous catalysts turned out to be as efficient as the homogeneous counterpart in the case of 3,5DTBC, with the advantage of being easier to separate and potentially recyclable.

Table 2 Oxidation of the 3,5-DTBC with Mn-based catalysts ${ }^{a}$

\begin{tabular}{lllll}
\hline Entry & Catalyst & Base (\%) & Conversion (\%) & Selectivity $^{b}(\%)$ \\
\hline 0 & - & - & 0 & 0 \\
1 & - & 200 & $\sim 20^{c}$ & 0 \\
2 & $\mathrm{MnCl}_{2}$ & 0 & 100 & 100 \\
3 & $\mathrm{MnCl}_{2}$ & 10 & 100 & 100 \\
4 & {$[\mathbf{M n}]$} & 10 & 100 & 100 \\
5 & {$[\mathbf{M n}]^{d}$} & 10 & 100 & 100 \\
6 & $\mathbf{S 1}$ & 0 & 100 & 100 \\
7 & $\mathbf{S} 2$ & 0 & 100 & 100
\end{tabular}

${ }^{a}\left[\mathrm{Mn}_{2} \mathrm{~L}_{2}(\mathrm{Cl})_{2}(\mu-\mathrm{Cl})_{2}\right]=[\mathrm{Mn}] ;\{\mathrm{Mn}\}$-Py@LUS-E15 = S1; $\{\mathrm{Mn}\}$-TMS@LUS$\mathrm{E}=$ S2. Standard reaction conditions: $50 \mathrm{~mL} \mathrm{MeOH}, 0.25 \mathrm{mmol} 3,5-$ DTBC, $10 \%$ catalyst, $\mathrm{O}_{2}$, room temperature, $5 \mathrm{~h}$; base $=2,2,6,6-$ tetramethylpiperidine. ${ }^{b}$ Selectivity for product A. ${ }^{c}$ Presence of unknown products. ${ }^{d} T=65{ }^{\circ} \mathrm{C}$.

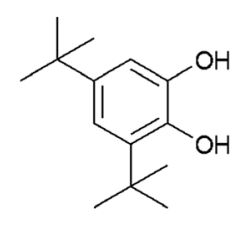

3,5-DTBC

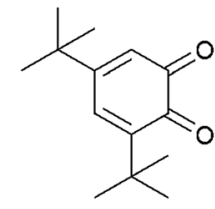

$\underline{A}$
Scheme 5 3,5-DTBC and its quinone equivalent $A$.
We then turned our attention to a more complex substrate, the 4-t-butyl catechol (4-TBC), for which we mainly identified two products, named $\mathrm{B}^{16}$ and $\mathrm{C}$ (Scheme 6). ${ }^{47,48}$ Without catalyst and in the presence of base, a total conversion of 4-TBC to a mixture of unidentified products was obtained (Table 3, entry 1 ), whereas without base but in presence of $\left[\mathrm{Mn}_{2} \mathrm{~L}_{2}(\mathrm{Cl})_{2}(\mu-\mathrm{Cl})_{2}\right]$ no reaction occurred (entry 2). With both catalyst and base, a mixture of products $\mathrm{B}$ and $\mathrm{C}$ were isolated with a $100 \%$ total conversion (entry 3).

Changing the nature of oxidant (air instead of oxygen) led to a slight modification of the $\mathrm{B} / \mathrm{C}$ ratio in favour of $\mathrm{B}$ product (entries 3 and 4), whereas heating under reflux had almost no significant effect on this ratio (entries 4 and 5). Reducing the reaction time from $5 \mathrm{~h}$ (entry 4 ) to $3 \mathrm{~h}$ (entry 7 ) diminished the amount of $\mathrm{B}$ in favour of $\mathrm{C}$. We thus assume that there is equilibrium between $\mathrm{B}$ and $\mathrm{C}$ depending on the reaction conditions. Finally, using a catalytic amount of base considerably diminished the activity of the catalyst (entries 4 and 6). Concerning the nature of the catalyst, with either $\mathrm{Mn}\left(\mathrm{NO}_{3}\right)_{2}$ (entry 8) or $\mathrm{MnCl}_{2}$ (entry 9) no reaction occurred, which proves that the ligand $\mathbf{L}$ is required for the activity of the catalyst (entry 10). In the absence of base, the heterogeneous catalysts had almost no activity in the case of 4-TBC (entries 11 and 12), whereas it showed oxidase activity with 3,5-DTBC. In the former case, an addition of stoichiometric amount of base was required to go to completion, leading selectively to only one compound, product B (entry 13). Indeed 3,5 -DTBC is easier to oxidise since the intermediates are more stable. ${ }^{49,50}$ It is noteworthy that in all cases no notable changes were observed in the $\mathrm{N}_{2}$ sorption isotherms, before and after catalytic tests, leading us to believe that the material do not undergo major modifications throughout the whole catalytic process (Fig. S3†). Nonetheless it remains to study the recyclability of these bio-inspired catalysts.

\section{Experimental}

\section{Chemicals}

All chemicals were used without further purification. Solvents were dried using molecular sieves if needed. Propargylamine, 2-picolyl chloride hydrochloride and 3-chloropropyltriethoxysilane were purchased from Sigma-Aldrich, tetrabutylammonium iodide and 2,2,6,6-tetramethylpiperidine were purchased from Acros Organics, tetramethylammonium bromide, hexamethyldisilazane were purchased from Alfa Aesar, 2-(4-pyridylethyl)triethoxysilane was provided by ABCR and bromotris(triphenylphosphine)copper bromide was purchased from Santa Cruz Biotechnology.

\section{Synthesis of the ligand and the azide tether}

Synthesis of the ligand $\mathbf{L}^{51}$ A mixture of propargylamine $(1.50 \mathrm{~g}, 27.3 \mathrm{mmol})$ and potassium carbonate $(22.8 \mathrm{~g}, 163.8 \mathrm{mmol})$ was stirred in $140 \mathrm{~mL}$ of acetonitrile for $5 \mathrm{~min}$. Then 2-picolyl chloride hydrochloride $(9.84 \mathrm{~g}, 60.0 \mathrm{mmol})$ dissolved in $140 \mathrm{~mL}$ of acetonitrile was added. The resulting solution was stirred under reflux for 5 days. The solution was filtered and the filtrate was evaporated under reduced pressure. The resulting brown oil was 
Table 3 Oxidation of 4-TBC with Mn-based catalysts ${ }^{a}$

\begin{tabular}{|c|c|c|c|c|c|c|}
\hline \multirow[b]{2}{*}{ Entry } & \multirow[b]{2}{*}{ Catalyst } & \multirow[b]{2}{*}{ Base (\%) } & \multirow[b]{2}{*}{ Oxidant } & \multirow[b]{2}{*}{ Conversion (\%) } & \multicolumn{2}{|c|}{ Selectivity (\%) } \\
\hline & & & & & B & $\mathrm{C}$ \\
\hline 2 & [Mn] & 0 & $\mathrm{O}_{2}$ & 0 & 0 & 0 \\
\hline 3 & [Mn] & 200 & $\mathrm{O}_{2}$ & 100 & 60 & 40 \\
\hline 4 & [Mn] & 200 & Air & 100 & 74 & 26 \\
\hline 7 & {$[\mathbf{M n}]$} & 200 & $\operatorname{Air}^{d}$ & 100 & 38 & 62 \\
\hline 8 & $\mathrm{Mn}\left(\mathrm{NO}_{3}\right)_{2}$ & 10 & $\mathrm{O}_{2}$ & 0 & 0 & 0 \\
\hline 9 & $\mathrm{MnCl}_{2}$ & 10 & $\mathrm{O}_{2}$ & 0 & 0 & 0 \\
\hline 10 & {$[\mathbf{M n}]$} & 10 & $\mathrm{O}_{2}$ & 70 & 100 & 0 \\
\hline 11 & S1 & 0 & $\mathrm{O}_{2}$ & $<5$ & $<5$ & 0 \\
\hline 12 & S2 & 0 & $\mathrm{O}_{2}$ & $<5$ & $<5$ & 0 \\
\hline
\end{tabular}

${ }^{a}\left[\mathrm{Mn}_{2} \mathrm{~L}_{2}(\mathrm{Cl})_{2}(\mu-\mathrm{Cl})_{2}\right]=[\mathrm{Mn}] ;\{\mathrm{Mn}\}$-Py@LUS-E15 = S1; $\{\mathrm{Mn}\}$-TMS@LUS-E = S2. Standard reaction conditions: $50 \mathrm{~mL} \mathrm{MeOH,} \mathrm{0.25} \mathrm{mmol} \mathrm{4-TBC,} \mathrm{10 \%}$ catalyst, $\mathrm{O}_{2}$, room temperature, $5 \mathrm{~h}$; base $=2,2,6,6$-tetramethylpiperidine. ${ }^{b}$ Mixture of unidentified products. ${ }^{c} T=65{ }^{\circ} \mathrm{C} .{ }^{d} 3 \mathrm{~h}$.<smiles>CC(C)(C)c1ccc(O)c(O)c1</smiles>

4-TBC

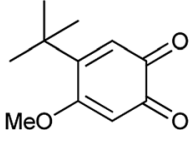

$\underline{B}$

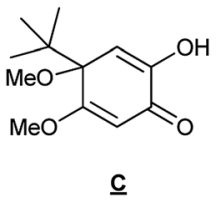

$\underline{\mathbf{C}}$
Scheme 6 4-TBC and the two main oxidation products B and C.

dissolved in $100 \mathrm{~mL}$ of distilled water and extracted with dichloromethane (3 times). The organic phases were gathered and dried over sodium sulphate. The solvent was finally evaporated to afford $\mathbf{L}$ in a $94 \%$ yield. ${ }^{1} \mathrm{H}$ NMR $\left(\mathrm{CDCl}_{3}, 300 \mathrm{MHz}\right)$ : $\delta(\mathrm{ppm}) 8.55(\mathrm{ddd}, J=4.80,1.80,0.90 \mathrm{~Hz}, 2 \mathrm{H}), 7.64(\mathrm{td}, J=7.50$, $1.80 \mathrm{~Hz}, 2 \mathrm{H}), 7.50(\mathrm{~d}, J=7.80 \mathrm{~Hz}, 2 \mathrm{H}), 7.15$ (ddd, $J=7.50,4.80$, $1.20 \mathrm{~Hz}, 2 \mathrm{H}), 3.91(\mathrm{~s}, 4 \mathrm{H}), 3.41(\mathrm{~d}, J=2.40 \mathrm{~Hz}, 2 \mathrm{H}), 2.29(\mathrm{t}, J=$ $2.40 \mathrm{~Hz}, 1 \mathrm{H}) \cdot{ }^{13} \mathrm{C}$ NMR $\left(300 \mathrm{MHz}, \mathrm{CDCl}_{3}\right): \delta(\mathrm{ppm}) 158.76,149.26$, 136.47, 123.14, 122.10, 78.32, 73.62, 59.44, 42.54. IR (KBr): 3294 (w), $3062(\mathrm{w}), 3011(\mathrm{w}), 2921(\mathrm{w}), 2839(\mathrm{w}), 2095(\mathrm{~m}, \mathrm{C} \equiv \mathrm{C}) \mathrm{cm}^{-1}$.

Synthesis of 3-azidopropyltriethoxysilane. ${ }^{31}$ Sodium azide $(27 \mathrm{~g}, 0.41 \mathrm{~mol})$ was added portionwise to a solution of 3chloropropyltriethoxysilane $(20 \mathrm{~g}, 83 \mathrm{mmol})$ and tetrabutylammonium iodide ( $153 \mathrm{mg}, 0.42 \mathrm{mmol}$ ) in $220 \mathrm{~mL}$ of butanone. The mixture was then stirred at reflux for $5 \mathrm{~d}$ under nitrogen. The solution was then filtered over celite and the solvent was removed under reduced pressure. The resulting oil

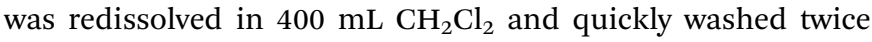
with $20 \mathrm{~mL}$ of distilled water. The organic phase was dried over $\mathrm{Na}_{2} \mathrm{SO}_{4}$ and the solvent was removed under reduced pressure to afford the 3-azidopropyltriethoxysilane $(84 \mathrm{mg}, 0.34 \mathrm{mmol})$ as a pale yellow oil in a $80 \%$ yield. ${ }^{13} \mathrm{C} \mathrm{NMR}\left(200 \mathrm{MHz}, \mathrm{CDCl}_{3}\right)$ : $\delta(\mathrm{ppm})$ 58.16, 53.54, 22.39, 17.97, 7.33.

\section{Synthesis of the grafted complexes}

$\left[\mathrm{Mn}_{2} \mathrm{~L}_{2}(\mathrm{Cl})_{2}(\mu-\mathrm{Cl})_{2}\right]$ was used to synthesise the hybrid materials. ${ }^{18}$ The complex was incorporated in a LUS mesoporous silica where azide functions were previously grafted using the so-called molecular stencil pattering technique. ${ }^{34} \mathrm{~A}$ Berghof speedwave oven was used for the synthesis of the mesoporous silica LUS using the procedure described elsewhere. ${ }^{18,30}$ It provides a microwave irradiation at $2450 \mathrm{MHz}$ with a power of $1450 \mathrm{~W}$. The experimental conditions used were: $T=180{ }^{\circ} \mathrm{C}$, ramp $=1 \mathrm{~min}$, plateau $=9 \mathrm{~min}($ total heating time $=10 \mathrm{~min}){ }^{30}$

Synthesis of LUS-TMA. ${ }^{34}$ Tetramethylammonium bromide $(1.7 \mathrm{~g}, 11 \mathrm{mmol})$ was dissolved in $150 \mathrm{~mL}$ of EtOH $70 \%$ and stirred for $10 \mathrm{~min}$ at $40{ }^{\circ} \mathrm{C}$. The LUS mesoporous silica $(3 \mathrm{~g})$ was added and the resulting suspension was stirred for $45 \mathrm{~min}$ at $40^{\circ} \mathrm{C}$. The solid was filtered on Büchner and washed twice with $50 \mathrm{~mL}$ of EtOH $70 \%$ and twice with $50 \mathrm{~mL}$ of acetone. This procedure was repeated three times to ensure a total exchange. The solid LUSTMA obtained was finally dried in at $80{ }^{\circ} \mathrm{C}$ overnight.

\section{Synthesis of \{Mn\}-Py@LUS-E15 (S1)}

LUS-TMA-E15. Hydrochloric acid ( $0.25 \mathrm{~mL}$ of $1 \mathrm{M}$ solution) was added to a suspension of LUS-TMA $(1 \mathrm{~g})$ in $200 \mathrm{~mL}$ of technical EtOH and stirred at RT for $1 \mathrm{~h}$. The solid was then filtered and washed twice with $100 \mathrm{~mL}$ of technical EtOH, before being dried overnight at $80^{\circ} \mathrm{C}$.

Py@LUS-TMA-E15. LUS-TMA-E15 (500 mg) was pretreated as at $130{ }^{\circ} \mathrm{C}$ under argon for $2 \mathrm{~h}$, then at $130^{\circ} \mathrm{C}$ under vacuum for $2 \mathrm{~h}$. After cooling under argon, a solution of 2-(4-pyridylethyl)triethoxysilane (459 $\mathrm{mg}, 1.7 \mathrm{mmol}$ ) dissolved in $10 \mathrm{~mL}$ of dry toluene was added. The suspension was stirred for $1 \mathrm{~h}, 20 \mathrm{~mL}$ of toluene were added, and the mixture was stirred at $80{ }^{\circ} \mathrm{C}$ during $18 \mathrm{~h}$. After filtration and washing twice with $20 \mathrm{~mL}$ of toluene, $20 \mathrm{~mL}$ of technical EtOH and $20 \mathrm{~mL}$ of acetone, the solid was finally dried overnight at $80{ }^{\circ} \mathrm{C}$.

Py@LUS-E15. Hydrochloric acid ( $2 \mathrm{~mL}$ of $1 \mathrm{M}$ solution) was added to a suspension of Py@LUS-TMA-E15 $(1 \mathrm{~g})$ in $200 \mathrm{~mL}$ of technical EtOH and stirred at RT for $1 \mathrm{~h}$. The solid was then 
filtered and washed twice with $100 \mathrm{~mL}$ of technical EtOH, before being dried overnight at $80^{\circ} \mathrm{C}$.

$\mathbf{N}_{3}$-Py@LUS-E15. Py@LUS-E15 (500 mg) was pretreated following the same procedure used in the synthesis of Py@LUSTMA-E15. After cooling under argon, a solution of 3-azidopropyltriethoxysilane $(371 \mathrm{mg}, 1.5 \mathrm{mmol})$ dissolved in $10 \mathrm{~mL}$ of dry toluene was added. The suspension was stirred for $1 \mathrm{~h}, 20 \mathrm{~mL}$ of toluene were added, and the mixture was stirred at $80^{\circ} \mathrm{C}$ during $18 \mathrm{~h}$. After filtration and washing twice with $20 \mathrm{~mL}$ of toluene, $20 \mathrm{~mL}$ of technical EtOH and $20 \mathrm{~mL}$ of acetone, the solid was finally dried overnight at $80^{\circ} \mathrm{C}$. Elemental analysis: C: $9.78 \%, \mathrm{H}$ : $1.99 \%, \mathrm{~N}: 2.14 \%$.

\{Mn\}-Py@LUS-E15 (S1). N ${ }_{3}$-Py@LUS-E15 (300 mg) was stirred in a mixture $\mathrm{MeOH} / \mathrm{MeCN}(60 \mathrm{~mL} / 20 \mathrm{~mL})$. After $10 \mathrm{~min}$, complex $\left[\mathrm{Mn}_{2} \mathrm{~L}_{2}(\mathrm{Cl})_{2}(\mu-\mathrm{Cl})_{2}\right](176 \mathrm{mg}, 0.5 \mathrm{mmol})$ was added and the suspension was stirred during $1 \mathrm{~h}$, before addition of $\mathrm{CuBr}\left(\mathrm{PPh}_{3}\right)_{3}(93 \mathrm{mg}, 0.10 \mathrm{mmol})$. Then the mixture was stirred at $60{ }^{\circ} \mathrm{C}$ for 6 days before filtration. The pale brown solid was washed with $200 \mathrm{~mL}$ of $\mathrm{MeOH}$ and dried overnight at $80{ }^{\circ} \mathrm{C}$. Elemental analysis: C: $9.86 \%$, H: $1.84 \%$, N: $1.68 \%$, Mn: $1.66 \%$, Cl: $0.74 \%$.

\section{Synthesis of \{Mn\}-TMS@LUS-E (S2) ${ }^{18}$}

TMS@LUS-TMA. ${ }^{34}$ Before any reaction, the solid was pretreated as follows: the LUS-TMA solid $(1.5 \mathrm{~g})$ was stirred at $130^{\circ} \mathrm{C}$ under argon for $2 \mathrm{~h}$, then at $130^{\circ} \mathrm{C}$ under vacuum for $2 \mathrm{~h}$. The solid was let to cool to room temperature under argon, before addition of hexamethyldisilazane $(2.42 \mathrm{mg}, 15.0 \mathrm{mmol})$ in $20 \mathrm{~mL}$ of dry toluene. The suspension was further stirred at room temperature for $1 \mathrm{~h}$, and $60 \mathrm{~mL}$ of toluene were then added. The suspension was stirred under argon at $80{ }^{\circ} \mathrm{C}$ for $18 \mathrm{~h}$, before being filtered and washed twice with $20 \mathrm{~mL}$ of toluene, $20 \mathrm{~mL}$ of technical EtOH and $20 \mathrm{~mL}$ of acetone. The solid was dried overnight at $80^{\circ} \mathrm{C}$ to afford the TMS@LUS-TMA silica.

TMS@LUS-E. Hydrochloric acid ( $2 \mathrm{~mL}$ of $1 \mathrm{MM}$ solution) was added to a suspension of TMS@LUS-TMA $(1 \mathrm{~g})$ in $200 \mathrm{~mL}$ of technical EtOH and stirred at RT for $1 \mathrm{~h}$. The solid was then filtered and washed twice with $100 \mathrm{~mL}$ of technical EtOH, before being dried overnight at $80{ }^{\circ} \mathrm{C}$.

$\mathbf{N}_{3}$-TMS@LUS-E and $\{$ Mn\}-TMS@LUS-E (S2). The functionalisation of TMS@LUS-E with azide functions and the incorporation of the $\mathrm{Mn}(\mathrm{II})$ complex $\left[\mathrm{Mn}_{2} \mathrm{~L}_{2}(\mathrm{Cl})_{2}(\mu-\mathrm{Cl})_{2}\right]$ in $\mathrm{N}_{3}-$ TMS@LUS-E was performed as described elsewhere. ${ }^{18}$ $\mathrm{CuBr}\left(\mathrm{PPh}_{3}\right)_{3}$ was used as catalyst and the reaction temperature and reaction time for the click reaction were $60{ }^{\circ} \mathrm{C}$ and 6 days, respectively.

\section{General procedure for the catalytic tests}

The substrate $(0.25 \mathrm{mmol})$ and the base (2,2,6,6-tetramethylpiperidine) were dissolved in $\mathrm{MeOH}(50 \mathrm{~mL})$ in a single-necked round-bottom flask. To this solution was added the catalyst and the gas was passed through the reaction mixture for $5 \mathrm{~h}$ with magnetic stirring.

Homogeneous catalysis. The resulting solution was concentrated to dryness and the resulting mixture was extracted with $\mathrm{Et}_{2} \mathrm{O}$ after addition of $2 \mathrm{~N} \mathrm{HCl}$ (until pH 4-5). The organic layer was dried over $\mathrm{MgSO}_{4}$. After evaporation of $\mathrm{Et}_{2} \mathrm{O}$, the crude mixture was analysed by ${ }^{1} \mathrm{H}$ NMR (300 MHz). Silica gel flashchromatography allowed separating the reaction products (80/ 20: petroleum ether/AcOEt).

Heterogeneous catalysis. Filtration of the reaction mixture allowed recovering of the catalyst for further analyses. The filtrate was concentrated to dryness, analysed by ${ }^{1} \mathrm{H}$ NMR (300 $\mathrm{MHz}$ ) and the reaction products were recovered by silica gel flash-chromatography (80/20: petroleum ether/AcOEt).

\section{Physico-chemical characterisation}

Infrared spectra were recorded from $\mathrm{KBr}$ pellets using a Mattson 3000 IRTF spectrometer. Nitrogen sorption isotherms at $77 \mathrm{~K}$ were determined with a volume device Belsorp Max on solids that were dried at $80{ }^{\circ} \mathrm{C}$ under vacuum overnight. Low angle $\mathrm{X}$ ray powder diffraction (XRD) experiments were carried out using a Brucker (Siemens) D5005 diffractometer using $\mathrm{Cu} \mathrm{K}$ monochromatic radiation. Liquid NMR spectra were recorded on a Bruker AC 200 spectrometer. Solid NMR spectra were measured on an Advance III Bruker $500 \mathrm{MHz}$ Wide Bore spectrometer, with a CP/MAS DVT (double resonance, variable temperature) probe $4 \mathrm{~mm}$. The delay time between pulses (pulse width $5 \mu \mathrm{s}$ ) in HPDEC experiments was set to $500 \mathrm{~s}$. Spinning speed was set to about $5 \mathrm{kHz}$ and the number of scans was 5000 . Frequency ${ }^{13} \mathrm{C}=125.76 \mathrm{MHz},{ }^{29} \mathrm{Si}=99.36 \mathrm{MHz}$. EPR spectra were recorded on a Brucker Elexsys e500 X-band (9.4 GHz) spectrometer with a 4102ST cavity (modulation: $2 \mathrm{G}$, power: 4 $\mathrm{mW}$ ). The simulated spectra were calculated using the Easyspin toolbox from Matlab. Variable-temperature magnetic susceptibility measurements were made using a Quantum Design MPMS-XL-5 SQUID susceptometer, using an applied field of $1000 \mathrm{G}$.

\section{Conclusions}

The $N, N^{\prime}$-bis[(pyridin-2-yl)methyl]prop-2-yn-1-amine (L) ligand is a versatile molecule allowing both coordination to a metal ion and grafting to a solid support using click chemistry. The functionalisation method herein reported is not restricted to this particular complex and can be applied to any metal complex provided that the ligand contains a free alkyne group. The site isolation is ensured by the molecular stencil patterning strategy that allows homogeneous grafting of two different functions in a precise ratio. The azide anchor function is surrounded by pyridyl or TMS functions. Once again, the method is not limited to these particular groups and can be extended to other isolating functions. We have demonstrated that the use of $\mathrm{CuBr}\left(\mathrm{PPh}_{3}\right)_{3}$ as catalyst for the Huisgen cycloaddition avoids copper complexation to $\mathbf{L}$ allowing therefore a better yield for the click reaction. The Mn hybrid materials here presented have been tested in the catalytic oxidation of two catechol derivatives (3,5-DTBC and 4-TBC). Their activity has been compared with that of the molecular analogue. With both catechol derivatives tested, oxidation could be achieved using molecular dioxygen as oxidant. This reaction can be compared to the natural oxidase 
enzymes. Nevertheless, the heterogeneous catalysts were more advantageous as no base was necessary in the case of 3,5-DTBC and only one product was obtained in the case of 4-TBC. Therefore, once grafted in a confined and controlled environment, the metal complex does exhibit a different and more advantageous behaviour than the free complex. The broad range of isolating functions available offers numerous options to control the activity of any inserted complex, which is not possible for complexes in solution. Controlling the environment at a larger range than the sole ligand might allow tuning the catalyst activity, in a similar fashion to the natural enzymes.

\section{Acknowledgements}

J. C. thanks the French "Ministère de l'Enseignement, de la Recherche et de la Technologie" (MERT) for a PhD fellowship, and the C-MIRA program of Rhône-Alpes region in France for financial support to the collaboration between the Universitat de València (Spain) and the Ecole Normale Supérieure de Lyon (France). The Spanish work was supported by the MICINN (Spain) (Project CTQ2010-15364) and the Generalitat Valenciana (Spain) (Projects PROMETEO/2009/108 and ISIC/2012/002).

\section{Notes and references}

1 B. C. Gates, Catalytic Chemistry, Wiley, 1992.

$2 \mathrm{~W}$. Kaim and B. Schwederski, Bioinorganic chemistry: Inorganic Elements in the Chemistry of Life, John Wiley \& Sons, 1st edn, 1994.

3 E. A. Lewis and W. B. Tolman, Chem. Rev., 2004, 104, 10471076.

4 L. M. Mirica, X. Ottenwaelder and T. D. P. Stack, Chem. Rev., 2004, 104, 1013-1045.

5 E. I. Solomon, U. M. Sundaram and T. E. Machonkin, Chem. Rev., 1996, 96, 2563-2605.

6 P. C. A. Bruijnincx, G. van Koten and R. J. M. K. Gebbink, Chem. Soc. Rev., 2008, 37, 2716-2744.

7 J. P. Emerson, M. L. Wagner, M. F. Reynolds, L. Que, M. J. Sadowsky and L. P. Wackett, J. Biol. Inorg Chem., 2005, 10, 751-760.

8 T. D. H. Bugg and S. Ramaswamy, Curr. Opin. Chem. Biol., 2008, 12, 134-140.

9 L. Que and M. F. Reynolds, Met. Ions Biol. Syst., 2000, 37, 505-525.

10 V. Georgiev, T. Borowski, M. R. A. Blomberg and P. E. M. Siegbahn, J. Biol. Inorg Chem., 2008, 13, 929-940.

11 J. P. Emerson, E. G. Kovaleva, E. R. Farquhar, J. D. Lipscomb and L. Que, Proc. Natl. Acad. Sci. U. S. A., 2008, 105, 73477352.

12 A. K. Whiting, Y. R. Boldt, M. P. Hendrich, L. P. Wackett and L. Que, Biochemistry, 1996, 35, 160-170.

13 H. Sakurai, S. Shimomura and T. Yoshimura, Biochem. Biophys. Res. Commun., 1983, 115, 618-624.

14 A. Ramadan and I. M. El-Mehasseb, Transition Met. Chem., 1998, 23, 183-189.

15 M. U. Triller, D. Pursche, W. Y. Hsieh, V. L. Pecoraro, A. Rompel and B. Krebs, Inorg. Chem., 2003, 42, 6274-6283.
16 N. Shaikh, A. Panja, P. Banerjee and M. Ali, Transition Met. Chem., 2003, 28, 871-880.

17 S. Calmettes, B. Albela, O. Hamelin, S. Menage, F. Miomandre and L. Bonneviot, New J. Chem., 2008, 32, 727-737.

18 J. Chaignon, S. E. Stiriba, F. Lloret, C. Yuste, G. Pilet, L. Bonneviot, B. Albela and I. Castro, Dalton Trans., 2014, 43, 9704-9713.

19 S. Abry, A. Thibon, B. Albela, P. Delichère, F. Banse and L. Bonneviot, New J. Chem., 2009, 33, 484-496.

20 V. Jollet, B. Albela, K. Senechal-David, P. Jegou, E. Kolodziej, J. Sainton, L. Bonneviot and F. Banse, Dalton Trans., 2013, 42, 11607-11613.

21 W.-J. Zhou, B. Albela, M.-Y. He and L. Bonneviot, Polyhedron, 2013, 64, 371-376.

22 C. T. Kresge, M. E. Leonowicz, W. J. Roth, J. C. Vartuli and J. S. Beck, Nature, 1992, 359, 710-712.

23 D. Brunel, N. Bellocq, P. Sutra, A. Cauvel, M. Lasperas, P. Moreau, F. Di Renzo, A. Galarneau and F. Fajula, Coord. Chem. Rev., 1998, 178, 1085-1108.

24 K. Moller and T. Bein, Chem. Mater., 1998, 10, 2950-2963.

25 D. E. De Vos, M. Dams, B. F. Sels and P. A. Jacobs, Chem. Rev., 2002, 102, 3615-3640.

26 H. C. Kolb, M. G. Finn and K. B. Sharpless, Angew. Chem., Int. Ed., 2001, 40, 2004-2021.

27 H. C. Kolb and K. B. Sharpless, Drug Discovery Today, 2003, 8, 1128-1137.

28 J. E. Moses and A. D. Moorhouse, Chem. Soc. Rev., 2007, 36, 1249-1262.

29 L. Bonneviot, M. Morin and A. Badiei, Patent, WO 01/55 031A031, 2001.

30 J. Chaignon, Y. Bouizi, L. Davin, N. Calin, B. Albela and L. Bonneviot, Green Chem., 2015, 17, 3130-3140.

31 M. Ortega-Munoz, J. Lopez-Jaramillo, F. Hernandez-Mateo and F. Santoyo-Gonzalez, Adv. Synth. Catal., 2006, 348, 2410-2420.

32 S. Abry, B. Albela and L. Bonneviot, C. R. Chim., 2005, 8, 741752.

33 A. Badiei, L. Bonneviot, N. Crowther and G. M. Ziarani, J. Organomet. Chem., 2006, 691, 5911-5919.

34 K. Zhang, B. Albela, M. Y. He, Y. M. Wang and L. Bonneviot, Phys. Chem. Chem. Phys., 2009, 11, 2912-2921.

35 M. W. Vetting, L. P. Wackett, L. Que, J. D. Lipscomb and D. H. Ohlendorf, J. Bacteriol., 2004, 186, 1945-1958.

36 V. Georgiev, T. Borowski and P. E. M. Siegbahn, J. Biol. Inorg Chem., 2006, 11, 571-585.

37 S. Huang, R. J. Clark and L. Zhu, Org. Lett., 2007, 9, 49995002.

38 W. S. Brotherton, H. A. Michaels, J. T. Simmons, R. J. Clark, N. S. Dalal and L. Zhu, Org. Lett., 2009, 11, 4954-4957.

39 K. Buerglova, N. Moitra, J. Hodacova, X. Cattoen and M. W. C. Man, J. Org. Chem., 2011, 76, 7326-7333.

40 I. Romero, M. N. Collomb, A. Deronzier, A. Llobet, E. Perret, J. Pecaut, L. Le Pape and J. M. Latour, Eur. J. Inorg. Chem., 2001, 69-72.

41 J. Z. Wu, E. Bouwman, A. M. Mills, A. L. Spek and J. Reedijk, Inorg. Chim. Acta, 2004, 357, 2694-2702. 
42 G. A. van Albada, A. Mohamadou, W. L. Driessen, R. de Gelder, S. Tanase and J. Reedijk, Polyhedron, 2004, 23, 2387-2391.

43 F. H. Kohler, N. Hebendanz, G. Muller, U. Thewalt, B. Kanellakopulos and R. Klenze, Organometallics, 1987, 6, 115-125.

44 B. Brauer, D. Schaarschmidt, C. Flohrer, T. Ruffer, S. Tripke, A. Hildebrandt, B. Walfort, L. Sorace and H. Lang, Inorg. Chim. Acta, 2011, 365, 277-281.

45 K. S. Banu, T. Chattopadhyay, A. Banerjee, M. Mukherjee, S. Bhattacharya, G. K. Patra, E. Zangrando and D. Das, Dalton Trans., 2009, 8755-8764.
46 I. C. Szigyarto, L. I. Simandi, L. Parkanyi, L. Korecz and G. Schlosser, Inorg. Chem., 2006, 45, 7480-7487.

47 T. R. Demmin and M. M. Rogic, J. Org. Chem., 1980, 45, 4210-4214.

48 M. Lanfranchi, L. Prati, M. Rossi and A. Tiripicchio, J. Mol. Catal. A: Chem., 1995, 101, 75-80.

49 J. Mukherjee and R. Mukherjee, Inorg. Chim. Acta, 2002, 337, 429-438.

50 J. Reim and B. Krebs, J. Chem. Soc., Dalton Trans., 1997, 3793-3804.

51 J. Rosenthal and S. J. Lippard, J. Am. Chem. Soc., 2010, 132, 5536-5537. 